\title{
Pathogenesis and Clinical Significance of Dermatophytes
}

\author{
Shyama Datt* and Thakur Datt \\ Department of Microbiology, UCMS \& GTB Hospital, Dilshad Garden, Delhi-95, India \\ *Corresponding author
}

Keywords

Dermatophytes,

Pathogenesis,

Trichophyton,

Microsporum,

Ergosterol

Article Info

Accepted:

17 October 2019

Available Online:

10 November 2019

\section{A B S T R A C T}

Despite the superficial localization of most dermatophytosis, host-fungus relationship in these infections is complex and still poorly elucidated. Though many efforts have been accomplished to characterize secreted dermatophytic proteases at the molecular level, only punctual insights have been afforded into other aspects of the pathogenesis of dermatophytosis, such as fungal adhesion, regulation of gene expression during the infection process, and immunomodulation by fungal factors. However, new genetic tools were recently developed, allowing a more rapid and high-throughput functional investigation of dermatophyte genes and the identification of new putative virulence factors. In addition, sophisticated in vitro infection models are now used and will open the way to a more comprehensive view of the interactions between these fungi and host epidermal cells, especially keratinocytes.

\section{Introduction}

\section{Dermatophytes}

Infections pertaining to mankind particularly those affecting the keratinized tissues are of serious concerns worldwide and are increasing on a global scale. Dermatomycoses are infections of the skin, hair and nail caused as a result of colonization of the keratinized layers of the body. This colonization is brought about by the organisms belonging to the three genera namely Trichophyton, Microsporum and
Epidermophyton $(1,2)$. Due to their high affinity for the keratinized tissues, dermatophytes are responsible for most of superficial mycosis affecting human skin or nails.

\section{Classification}

Dermatophytes are fungi that invade and multiply within keratinized tissues (skin, hair, and nails) causing infection (1). Based upon their genera, Dermatophytes can be classified into three groups: Trichophyton (which causes 
infections on skin, hair, and nails), Epidermophyton (which causes infections on skin and nails), and Microsporum (which causes infections on skin and hair). Based upon the mode of transmission, these are been classified as anthropophillic, zoophilic, and geophilic. Finally, based upon the affected site, these are been classified clinically into tinea capitis (head), tinea faciei (face), tinea barbae (beard), tinea corporis (body), tinea manus (hand), tinea cruris (groin), tinea pedis (foot), and tinea unguium (nail).Other clinical variants include tinea imbricata, tinea pseudoimbricata, and Majocchi granuloma(3).

\section{Trichophyton}

The genus Trichophyton includes 24 species. The colonies on agar media are powdery, velvety or waxy. The predominant spore type is micro conidia with sparse macro conidia (4).

\section{Microsporum}

The genus Microsporum includes 16 species. The colony morphology of Microsporum species on agar surface is either velvety or powdery with white to brown pigmentation (4).

\section{Epidermophyton}

The genus Epidermophyton includes only 2 species. The colonies are slow-growing, powdery and unique brownish yellow in colour. This genus is devoid of micro conidia. Macro conidia are abundant and produced in clusters (4).

Distribution frequency of dermatophytes and dermatophytosis

All the three genera of Dermatophytes namely Trichophyton, Microsporum and Epidermophyton are worldwide in geographical distribution. The predominant cause of Dermatophytic infections is Trichophyton followed by Epidermophyton and Microsporum. Within the genus Trichophyton, Trichophyton rubrum is the predominant etiological agent accounting for $69.5 \%$ followed by Trichophyton mentagrophytes, Trichophyton verrucosum and Trichophyton tonsurans (5-7).

According to the World Health Organization (WHO) survey on the incidence of dermatophytic infection, about $20 \%$ the people worldwide present with cutaneous infections (8).

\section{Pathogenesis and clinical presentation}

The possible route of entry for the Dermatophytes into the host body is injured skin, scars and burns. Infections caused by arthrospores or conidia. Resting hairs lack the essential nutrient required for the growth of the organism. Hence, these hairs not invaded during the process of infection (22).

The pathogen invades the uppermost, nonliving, keratinized layer of the skin namely the stratum corneum, produces exo-enzyme keratinase and induces inflammatory reaction at the site of infection (23-26). The customary signs of inflammatory reactions such as redness (ruber), swelling (induration), are seen at the infection site. Inflammation causes the pathogen to move away from the site of infection and take residence at a new site. This movement of the organism away from the infection site produces the classical ringed lesion (27) (Fig. 1-4).

Figure 3: The schematic route of entry of dermatophytes into the host system and onset the host when pathogen entry.

The infections caused by Dermatophytes commonly referred to as "tinea" or "ring- 
worm" infections due to the characteristic ringed lesions (9). Based on the site of infection, the tinea infections are referred to as tinea capitis (scalp), tinea corporis or tinea circinata (non-hairy, glaborous region of the body), tinea pedis ("Athletes' foot"; foot), tinea ungium ("Onychomycosis"; nail), tinea mannum (hands) (Figure 3), tinea barbae ("Barbers' itch"; bearded region of face and neck), tinea incognito (steroid modified), tinea imbricata (modified form of tinea corporis), tinea gladiatorial (common among wrestlers') and tinea cruris(“Jocks' itch"; groin) (10).

Dermatophytes can survive solely on outer cornified layers of the skin. $(11,12)$ The ability of certain fungi to adhere to particular host arises from numerous mechanisms and host factors, including the ability to adapt to the human body.(11) Natural infection is acquired by the deposition of viable arthrospores or hyphae on the surface of the susceptible individual.(13) After the inoculation in the host skin, suitable conditions favor the infection to progress through the following stages.(14)

\section{Adherence}

The kinetics of adherence to the skin or nail surface was investigated in several Trichophyton and Microsporum species, using different experimental models and microscopy techniques. These studies showed a timedependent increase in the number of adhering spores, followed by germination and invasion of the stratum corneum by hyphae growing in multiple directions. Zurita and Hay (14) observed that maximum adherence of Trichophyton spp. arthroconidia to keratinocytes in suspension occurred within 3-4 h. Aljabre et al., $(15,16)$ used stripped sheets of stratum corneum or separate keratinocytes to demonstrate that adherence of Trichophyton mentagrophytes arthroconidia is maximum by $6 \mathrm{~h}$ and that germination of these spores begins by $4 \mathrm{~h}$. In a nail plate model, adherence and germination of $T$. mentagrophytes arthrospores were observed at $6 \mathrm{~h}$ and side branches at $16 \mathrm{~h}$ (17). The early stages of $T$. mentagrophytes infection were investigated using skin explants of full epidermis thickness (18). Adherence was maximum at $12 \mathrm{~h}$, germination had started by $24 \mathrm{~h}$, and penetration of the stratum corneum occurred after 3 days.

Little is known about the factors that mediate adherence of dermatophytes. The ability of $\mathrm{T}$. rubrum to adhere to epithelial cells has been attributed to carbohydrate-specific adhesins, expressed on the surface of microconidia (19). From a morphological point of view, fibrillar projections have been observed in $T$. mentagrophytes during the adherence phase $(20,21)$. At the skin surface, long and sparse fibrils connect fungal arthroconidia to keratinocytes and to each other, while in the inner skin layers, newly formed arthroconidia show thin and short appendices covering their entire surface; the latter beg into vanish as a large contact area is established between conidia and skin tissue (21). Based on the findings made in the yeast Candida albicans, where secreted aspartic proteases (Saps) have been shown to play a fundamental role in fungal adherence to epithelia (22-23), so that is dermatophytic-secreted proteases could facilitate or even be necessary for efficient adherence. We have checked the expression pattern of Exoprotease and Endoprotease genes with their non-protease genes in real time PCR from that data we hypothesised that the Endoprotease have majorly expressed in dermatophytic patient during infection.

\section{Penetration}

Dermatophytes are provided with an arsenal of proteases aimed at the digestion of the keratin network into assimilable oligopeptides or amino acids. (24) Once established, the spores 
must germinate and penetrate the stratum corneum at a rate faster than desquamation. Penetration is accompanied by dermatophytes secreting multiple serine-subtilisins and metallo-endoproteases (fungalysins) formerly called keratinases that are found almost exclusively in the dermatophytes.(24,25) A direct relationship between keratinases and pathogenicity was established by Viani et al., The protease production in T. rubrum is highly host specific showing reduced physiological activity when growing on their preferred host $(26,27)$.

\section{Immunity behind dermatophytic infection}

\section{Development of host response}

Fungal metabolic products diffuse through the malphigian layer to cause erythema, vesicle or even pustule formation along with pruritus. Their in vivo activity is restricted to the zone of differentiation, newly differentiated keratin and Adamson's fringe within the hair shaft.(28) Acute dermatophytosis is associated with a DTH skin response against them, while persistent disease corresponds to IH responses, to high levels of IgE and IgG4 antibodies, and to the production of $\mathrm{Th} 2$ cytokines by mononuclear leukocytes.(29)

\section{Acquired resistance}

The efficient and protective response against dermatophytosis is a cell-mediated response of the DTH, characterized namely by the action of macrophages as effector cells, interferon- $\alpha$ secretion from type 1 T-helper lymphocytes and by some key cytokines like interferon- $\gamma$ (IFN- $\gamma$ ). Immune detection and chemotaxis occur via low-molecular weight chemotactic factors or alternative complement pathway activation. However, the immune response that is raised, and especially the degree of inflammation, varies according to the dermatophyte species, the host species and the pathophysiological status of the host. In general, the zoophilic species cause more inflammatory infections, which may heal spontaneously and result in relative resistance to re-infection. The anthropophilic species usually cause more chronic, less circumscribed infections, which result in less resistance to re-infection (30). Primary infection produces negative trichophytin test and minimal inflammation (mild erythema and scaling) due to increased keratinocyte turnover.

\section{Antibodies}

Antibody formation does not seem to be protective (31). The dermatophyte antigen is thought to be processed by epidermal Langerhans cells and presented in local lymph nodes to $\mathrm{T}$ lymphocytes which proliferate, migrate to the infected site, and produce inflammation. The epidermal barrier becomes permeable to transferring and migrating cells leading to spontaneous resolution of lesions. Trichophytin skin test is now positive and clearing of second infection will be more rapid.(32) Rivalier showed that a dermatophytic infection in humans results in a relative resistance to subsequent infection (33)mainly by the inflammatory forms (kerion), caused by zoophilic species, but not always follow the more chronic anthropophilic infections. $(18,34)$ Barlow and Chattaway (34) pointed out that fungi which do not invade the hair follicle do not seem to give rise to an equivalent immunity when growing in the horny layer of the smooth skin. It demonstrate such acquired immunity in experimental $\mathrm{T}$. rubrum infection of smooth skin. $(19,35)$

\section{Hypersensitivity ("Trichophytin" reaction)}

Dermatophytid reactions (4-5\% of patients) are inflammatory eczematous allergic skin reactions at sites distant from primary fungal infection.(36) Being $\mathrm{KOH}$ and culture 
negative, it is associated with a DTH response to trichophytin test and may involve a local DTH response to systemically absorbed fungal antigen $(36,37)$.

\section{Treatment}

The treatment is chosen based on the infection site, etiological agent and penetration ability of the drug. The penetration ability and retention in the site of infection of the agent determines its efficacy and frequency of utility. Since the dermatophytes reside in the stratum corneum especially within the keratinocytes, the antifungal agents should have a good penetrating ability. The duration of treatment mainly depends on the type of infection and symptom. Generally a two-three week treatment is required for skin lesions whereas four-six week for feet inflammation (38).

The year 1970 saw the release of Miconazole, the first in the line of azoles group. Since then many more were subsequently synthesized and added to this list during the same period. These antimycotic drugs belonged to the Azoles class of antifungal drugs. The major target of the azoles unlike the other antifungal agents is the cytochrome P450 enzyme (39) (Figure 5).

Fig.1

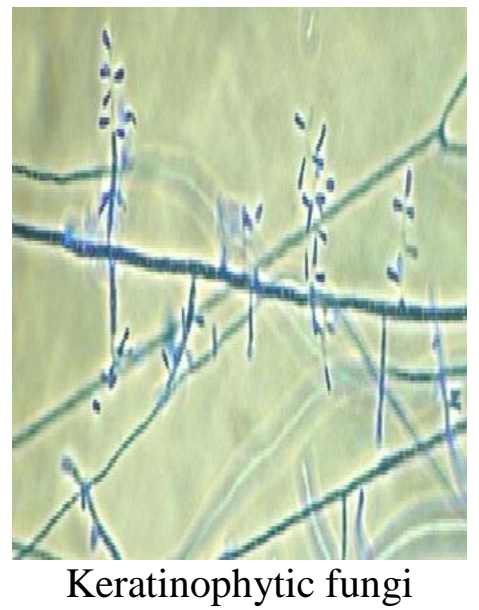

Fig.2

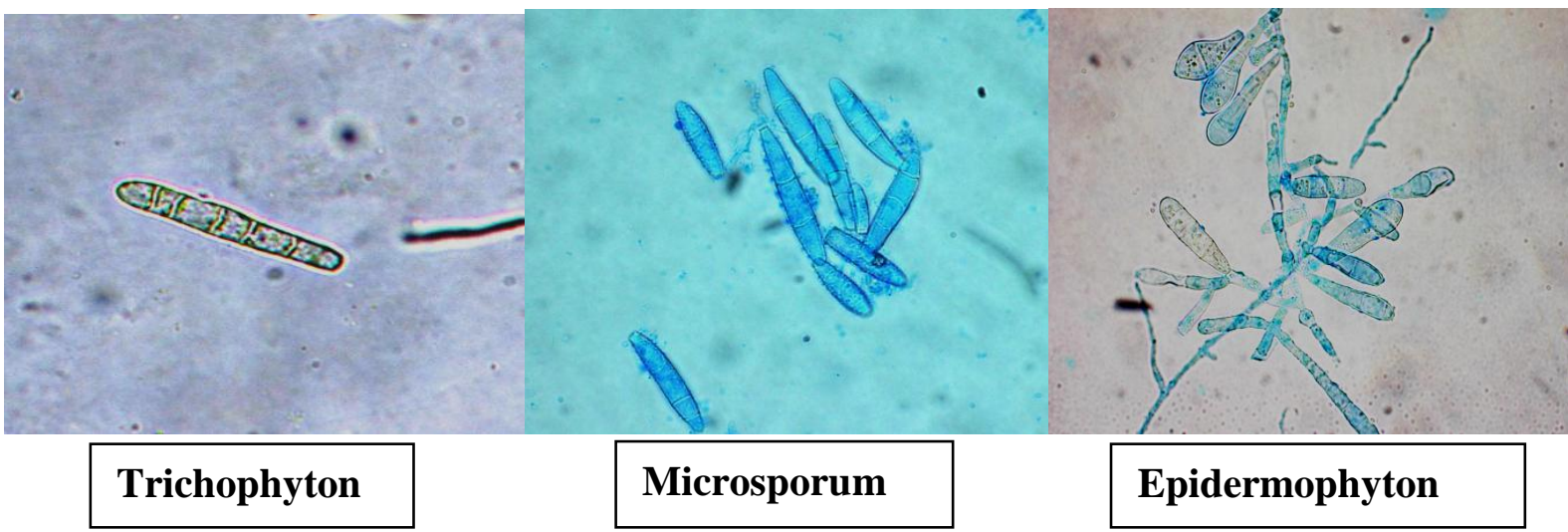




\section{Fig.3}

Spore from soil/animal/human

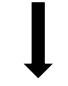

Dermatophytes

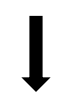

Enter stratum corneum

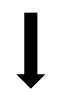

Release Keratin

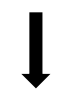

Sulfite efflux pump break down

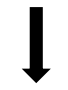

Release exoproteases

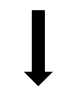

Release endoprotease

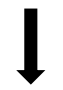

Infected the lesion

Fig.4

Tinea mannum

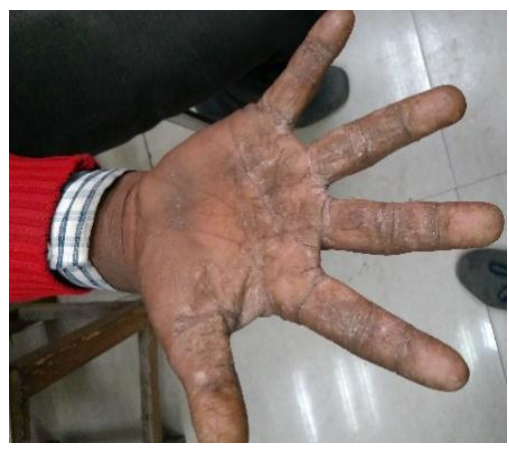

Tinea cruris

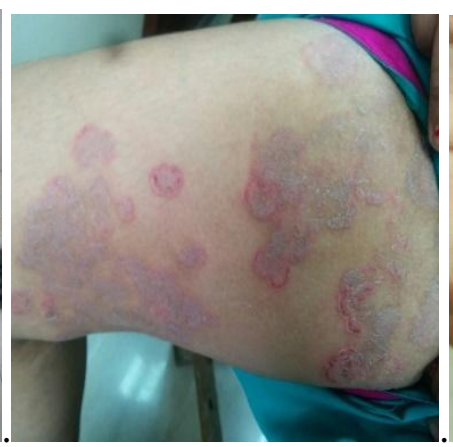

Tinea ungunium

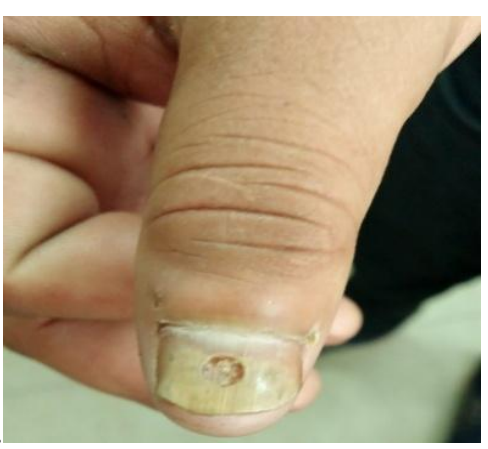


Fig.5 Ergosterol biosynthesis pathway

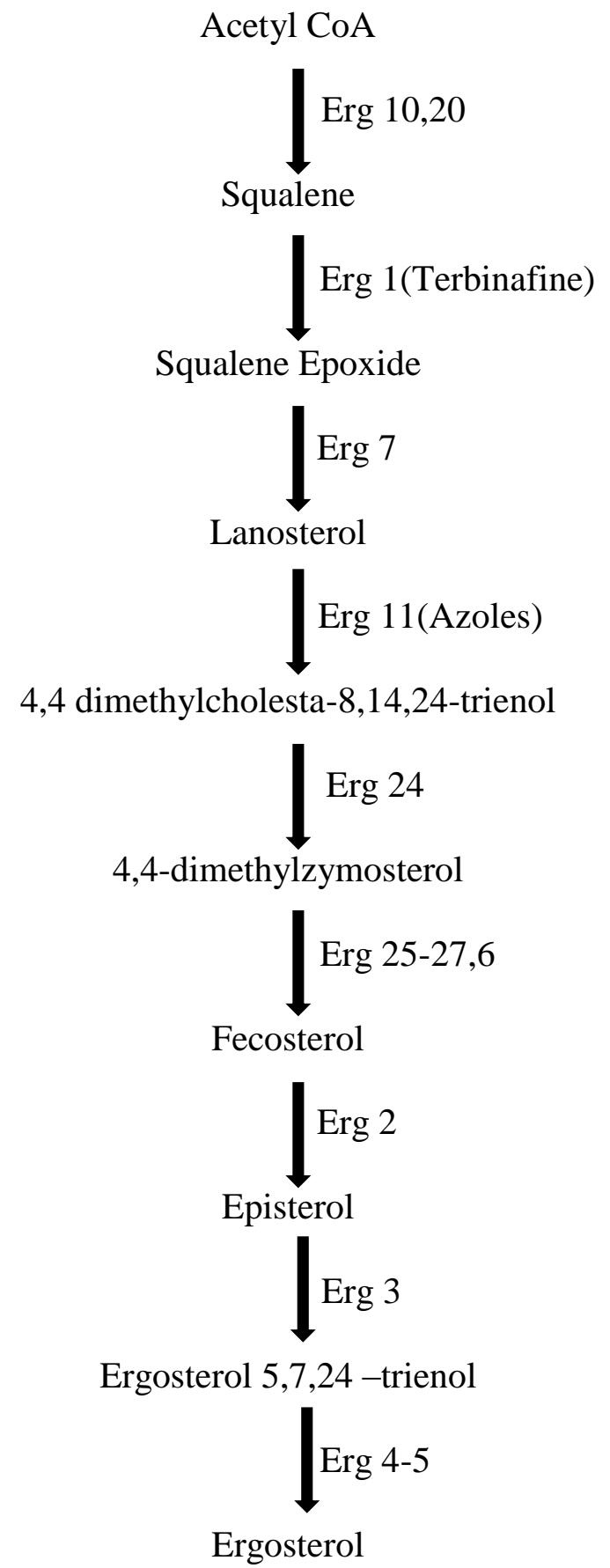

Based on the number of nitrogen atoms the azoles derivatives are classified into 2 groups as imidazoles and triazoles (40). In general the imidazoles exhibit side effects such as anorexia, constipation, headache, hepatitis, pruritis, exanthema and inhibition of synthesis of steroid hormone (41). Triazoles include fluconazole, voriconazole, itraconazole (1980), posaconazole, teraconazole and ravuconazole. In comparison to the imidazoles, the triazoles exhibit lesser degree of sideeffects which includes nausea, dizziness 
and gastrointestinal upset (42). Allylamines and benzyl amines were synthesized in the 1980s'. Allylamines include naftifineand terbinafine. Naftifine, terbinafine and benzylamine obtained FDA approval in United States in the year 1988,1992 and 2001, respectively. The mode of action of these drugs is inhibition of the key enzyme squalene epoxidase, an essential enzyme involved in the synthesis of squalene epoxide from squalene (43)

Griseofulvin is an arrow spectrum antimycotic drug with fungistatic activity. It is very effective against all the dermatomycoses. The side effects include headache, nausea, bad taste, skin rash, systemic lupus erythematosus (SLE), porphyria and arthralgia. With all its side effects, griseofulvin still remains to be the gold-standard for treating dermatophytic infections (44). Treatment of cutaneous infection using natural sources is the ongoing research work of many research groups across the globe.

\section{A Novel Approach to Solve the Problem}

More recently the scientific community has turned its attention to secondary metabolites from actinobacteria and its exploitation for various purposes which include therapeutic, environmental and industrial applications.

With developing microbial resistance and need for safe and cost-effective antidermatophytic drugs, screening of actionbacteria for potential bioactive secondary metabolites becomes indispensible (45). The anti-dermatophytic activity of these three strains is anticipated to be due to high salt concentration of the environment. Under stress conditions microorganisms inhabiting the particular environment is said to produce complex chemicals that can be exploited medicinally.

\section{References}

Aljabre SH, Richardson MD, Scott EM, Rashid A, Shankland GS. Adherence of arthroconidia and germlings of anthropophilic and zoophilic varieties of Trichophyton mentagrophytes to human corneocytes as an early event in the pathogenesis of dermatophytosis. Clin Exp Dermatol. 1993;18:231-5.

Rashid A, Scott E, Richardson MD. Early events in the invasion of the human nail plate by Trichophyton mentagrophytes. $\mathrm{Br} \mathrm{J}$ Dermatol. 1995; 133: 932-40.

Aljabre SH, Richardson MD, Scott EM, Rashid A, Shankland GS. Adherence of arthroconidia and germlines of antropophilic and zoophilic varieties of T. mentagrophytes to human corneocytes as an early event in the pathogenesis of dermatophytosis. Clin Exp Dermatol 1993; 18: 231-5.

Aljabre SH, Richardson MD, Scott EM, Shankland GS. Germination of Trichophyton mentagrophytes on human stratum corneum in vitro. $\mathrm{J}$ Med Vet Mycol. 1992; 30: 145- 52.

Barlow AJ, Chattaway FW. The parasitism of ringworm group of fungi. AMA Arch Dermatol 1958;77:399-405.

Bristow IR, Spruce MC. Fungal foot infection, cellulitis and diabetes: a review. Diabet Med. 2009; 26: 548-51.

Chander J. Dermatophytoses, textbook of medical mycology. 1995; 1: 91-112.

Chen BK, Friedlander SF. Tinea capitis update: a continuing conflict with an old adversary. Current opinion in pediatrics. 2001 Aug 1; 13 (4): 331-5.

Ciavaglia MD, Decarvalho TU, Desouza W. Interaction of Trypanosoma cruzi with cells with altered glycosylation patterns. Biochemical and biophysical research communications. 1993 Jun 15; 193(2): 718-21.

Coloe SV, Baird RW. Dermatophyte infections in Melbourne: trends from 1961/64 to 
1995/96. Pathology. 1999 Jan 1; 31(4): 395-7.

Dahl MV. Dermatophytosis and the immune response. J Am Acad Dermatol 1994; 31: 34-41.

De Bernardis F, Liu H, O’Mahony R, La Valle $\mathrm{R}$, Bartollino S, Sandini S, Grant S, Brewis N, Tomlinson I, Basset RC, Holton J, Roitt IM, Cassone A. Human domain antibodies against virulence traits of Candida albicans inhibit fungus adherence to vaginal epithelium and protect against experimental vaginal candidiasis. J Infect Dis. 2007; 195: 149-57.

Deepika, T.L. and Kannabiran, K. (2009) A morphological, biochemical and biological studies of halophilic Streptomyces sp isolated from saltpan environment. American Journal of Infectious Diseases, 5(3), 207-213.

Desai SC, Bhat ML, Modi PJ. Biology of $T$. rubrum infections. Ind J Med Res 1963; 51: 233-43.

Duek L, Kaufman G, Ulman Y, Berdicevsky I. The pathogenesis of dermatophyte infections in human skin sections. J Infect. 2004; 48: 175-80.

Elewski, B.E. (1993) Mechanisms of action of systemic antifungal agents. Journal of the American Academy of Dermatology, 28(3), 28-34.

Elewski, B.E. and Hazen, P.G. (1989) The superficial mycoses and the dermatophytes. Journal of the American Academy of Dermatology, 21(4), 655673.

Emmons, C.W., Bindford, C.H., Utz, J.P. and Kwon- Chung, K.L. (1977) Dermatophytoses. Medical Mycology, 3rd Edition, Lea and Febiger, Philadelphia, 117-167.

Esquenazi D, Alviano CS, de Souza W, Rozental S. The influence of surface carbohydrates during in vitro infection of mammalian cells by the dermatophyte Trichophyton rubrum. Res Microbiol. 2004;155:144-53.
Gentles, J.C. (1958) Experimental ringworm of guinea pigs: Oral treatment with griseofulvin. Nature, 182(4633), 476477.

Grant, S.M. and Clissold, S.P. (1989) Itraconazole: A review of its pharmacodynamic and pharmacokinetic properties and therapeutic use in superficial and systemic mycosis. Drugs, 37(3), 310-344.

Grappel SF, Bishop CT, Blank F. Immunology of dermatophytes and dermatophytosis; Bacteriol Rev 1974; 38: 222-50.

Grappel SF, Bishop CT, Blank F. Immunology of dermatophytes and dermatophytosis; Bacteriol Rev 1974;38:222-50.

Hay RJ, Moore MK. 'Mycology' in textbook of dermatology. 7th ed., Vol. 2. Burns T, Breathnach S, Cox N, Griffiths C (eds), United States: Blackwell Oxford; 2004.

Hay RJ, Reid S, Talwat E, Macnamara K. Immune responses of patients with tinea imbricate. Br J Dermatol 1983;108:5816.

Jagdish, C. (1995) Dermatophytoses. Medical Mycology, 1st Etdition, 106-107.

Jagdish, C. (1996) Dermatophytoses. Medical Mycology, 1st Etdition, 108-109.

Kaaman T, Torssander J. Dermatophytid - A misdiagnosed entity? Acta Derm Venereol 1983; 63: 404-8.

Katsambas, A., Antoniou, C.H., Frangouli, E., Avgerinou, G., Michailidis, D. and Stratigos, J. (1989) A double blind trial of treatment of seborrhoic dermatitis with $2 \%$ ketaconazole cream compared with $1 \%$ hydrocortisone cream. British Journal of Dermatology, 12(Suppl 14), 353-357.

Kaufman G, Horwitz BA, Duek L, Ullman Y, Berdicevsky I. Infection stages of the dermatophyte pathogen Trichophyton: microscopic characterization and proteolytic enzymes. Med Mycol. 2007;45:149-55.

Luilma, A.G., Sidrimb, J.J.C., Domingos, T.M., Cechinel, V.F. and Vietla, S.R. (2005) In vitro antifungal activity of dragon's blood from Croton urucurana against 
dermatophytes. Journal of Ethnopharmacology, 97(2), 409-412.

Marques SA, Robles AM, Tortorano AM, Tuculet MA, Negroni R, Mendes RP. Mycoses associated with AIDS in the Third World. Medical Mycology. 2000 Dec 30; 38 (sup1):269-79.

Monod M, Borg-von Zepelin M. Secreted aspartic proteases as virulence factors of Candida species. Biol Chem. 2002; 383: 1087-93.

Ollert MW, Sohnchen R, Korting HC, Ollert U, Brautigam S, Brautigam W. Mechanisms of adherence of Candida albicans to cultured human epidermal keratinocytes. Infect Immun. 1993; 61: 4560-8.

Rippon JW, McGinnis MR. The changing epidemiology and emerging patterns of dermatophyte species. Current Topics in Medical Mycology. New York: Springer-Verlag; 1995. p. 209-34.

Rippon JW. Medical Mycology, the Pathogenic fungi and Pathogenic Actionmycetes. 3rd ed., Philadelphia: WB Saunders; 1988.

Rippon JW. Medical Mycology: The pathogenic Fungi and the Pathogenic Actinomycetes, 3rd edn. Philadelphia: Saunders; 1988.p.140-275.

Rivalier E. Recherches experimentales sur l'allergie et l'immunite trichophytiques. Ann. Dermatol. Syphiligr 1929;10:61840.

Samdani AJ: Dermatophyte growth and degradation of human stratum corneum in vitro (pathogenesis of dermatophytosis). J Ayub Med Coll Abbottabad 2005;17:19-21.

Sandy Vermout. Pathogenesis of dermatophytosis. Mycopathologia 2008;166:267-75.

Tabart J, Baldo A, Vermout S, Nusgens B, Lapiere C, Losson B, Mignon B. Reconstructed interfollicular feline epidermis as a model for Microsporum canis dermatophytosis. J Med Microbiol. 2007; 56: 971-5.

Verma Shannon, Heffernan M. In superficial fungal infections chapter 188 of Dermatology in general medicine. 7th ed., vol 2. Wolff K, Goldsmith LA, Katz SI, Gilchrest BA, Paller AS, Leffell DJ (eds.). New York: McGraw Hill; 2008.

White TC, Oliver BG, Gräser Y, Henn MR. Generating and testing molecular hypotheses in the dermatophytes. Eukaryotic cell. 2008 Aug 1; 7 (8):123845.

Wolverton, S.E. (2001) Systemic antifungal drugs. Comprehensive Dermatologic Drug Therapy, 2nd Edition, Saunders.

Woodfolk JA. Allergy and dermatophytes. Clinical microbiology reviews. 2005 Jan 1; 18 (1): 30-43.

Zurita J, Hay RJ. Adherence of dermatophyte microconidia and arthroconidia to human keratinocytes in vitro. J Invest Dermatol. 1987; 89: 529-34.

\section{How to cite this article:}

Shyama Datt and Thakur Datt. 2019. Pathogenesis and Clinical Significance of Dermatophytes. Int.J.Curr.Microbiol.App.Sci. 8(11): 1877-1886. doi: https://doi.org/10.20546/ijcmas.2019.811.220 